\title{
A FORMAÇÃO DO DOCENTE EM HISTÓRIA COMO PROFISSIONAL DO MAGISTÉRIO DA EDUCAÇÃO BÁSICA
}

\author{
TRAINING OF TEACHERS IN HISTORY AS A PROFESSIONAL TEACHING OF BASIC \\ EDUCATION
}

Crislane Azevedo ${ }^{1}$

\begin{abstract}
RESUMO: Neste texto discorremos sobre o desafio da formação de professores de História à luz das novas diretrizes curriculares nacionais para a formação inicial e continuada dos profissionais do magistério da Educação Básica e discutimos sobre possíveis encaminhamentos de propostas tendo em vista o repensar da organização e prática curricular dos cursos de formação docente inicial de História. Vivenciamos um período de discussões e levantamento de proposições tendo em vista reformas nos cursos de licenciatura. Professores formadores precisarão dedicar-se a um trabalho coletivo de revisões e encaminhamentos de reforma considerando as orientações das novas diretrizes curriculares para a formação de professores, aprovadas em junho de 2015 pelo Conselho Nacional de Educação. Tais encaminhamentos podem ser desenvolvidos de forma articulada tanto por meio da diversificação curricular das atividades do âmbito do ensino, quanto com o planejamento e institucionalização de ações de iniciação à pesquisa bem como de curricularização da extensão.
\end{abstract}

Palavras-chave: Docência em História. Diretrizes Curriculares Nacionais. Ensino, pesquisa e extensão.

\begin{abstract}
In this paper we carry on about the challenge of training of history teachers in the light of the new national curriculum guidelines for initial and ongoing training of Basic Education teaching professionals and discuss possible referral of proposals for rethinking the organization and curricular practice of initial teacher training courses of history. We experienced a period of discussions and lifting proposals with a view to reforms in degree courses. Teacher educators need to engage in a collective effort to review and reform referrals considering the guidelines of the new national curriculum guidelines for teacher training, approved in June 2015 by the National Council of Education. Such referrals can be developed in coordination both through curriculum diversification of the scope of teaching activities, as with planning and institutionalization of initiation of actions to research and extension curricularising.
\end{abstract}

Keywords: Teaching in History. National Curriculum Guideline. Teaching, research and extension.

1 Professora adjunta III do Departamento de Práticas Educacionais e Currículo e do Programa de Pós-Graduação em Educação, do Centro de Educação, da Universidade Federal do Rio Grande do Norte (UFRN). Doutora em Educação pela UFRN. 


\section{Introdução}

Discutir sobre formação de professores no ensino superior significa, em grande medida, discutir o ensino escolar que queremos (formação inicial) e que estamos fazendo (formação continuada) na educação básica. Essa relação aparentemente simplista, na verdade, constitui-se em um dos maiores e mais persistentes desafios dos que fazem as instituições formadoras. Isso revela que a relação entre a formação para o magistério e o exercício da docência não tem sido simples, mesmo no início do século XXI, período de contínuas discussões e regulamentações tanto a respeito da formação de professores quanto sobre o ensino na educação básica.

A partir de 2015, instaura-se mais um momento de discussões e levantamento de proposições tendo em vista reformas nos cursos de licenciatura. Dessa forma, professores formadores diretamente ligados às licenciaturas precisam dedicar-se a um trabalho coletivo de revisões e encaminhamentos de reforma considerando-se que as novas diretrizes curriculares nacionais (DCN) para a formação de professores, aprovadas em junho de 2015 pelo Conselho Nacional de Educação (CNE), instigam-nos a pensar não apenas em aspectos teóricos e metodológicos da formação, mas também em reordenamentos da organização e operacionalização dos componentes curriculares da licenciatura, decorrentes da ampliação da carga horária dos cursos. Diante do exposto, neste texto discorremos sobre o desafio da formação de professores de História à luz das novas diretrizes curriculares nacionais para a formação inicial e continuada dos profissionais do magistério da educação básica (BRASIL, 2015) e discutimos sobre possíveis encaminhamentos de propostas tendo em vista o repensar da organização e prática curricular dos cursos de formação docente inicial de História.

\section{Formação de professores e a base comum nacional}

Discutir formação de professores hoje implica no domínio de uma complexa multiplicidade de saberes. A temática por vezes encaminha-nos para aspectos 
relativos, entre outros, a: saberes docentes; didática; práticas pedagógicas; avaliação, financiamento e gestão da educação; identidade docente; contextualização e interdisciplinaridade; conhecimento e informação; prática educativa e políticas de inclusão; novas tecnologias da informação; promoção da diversidade curricular; relações entre ensino e aprendizagem e procedimentos de avaliação; articulação entre ensino e pesquisa. Esses são alguns dos aspectos que uma vez investigados, apontam para a relação, por vezes desarticulada, entre ensino superior e educação básica tomando como base o processo formativo de docentes, ou seja, para a relação nem sempre consistente entre o que se efetiva no período de formação como currículo ou matrizes curriculares e o que se busca vivenciar como Base Nacional Comum.

Definida pela Lei de Diretrizes e Bases (LDB) de 1996, a base nacional comum relaciona-se aos componentes curriculares da educação básica (Art. 26). De acordo com a LDB é preciso que se garanta igualdade de acesso aos alunos a uma base nacional comum. Ela se refere a um conjunto de conteúdos mínimos das áreas de conhecimento trabalhadas à luz de uma perspectiva de contextualização de conteúdos e práticas, ou seja, articuladas a vivências cognitivas e socioculturais dos alunos, portanto, relacionados a uma prática cidadã. Esses conteúdos mínimos das áreas de conhecimento são "noções e conceitos essenciais sobre fenômenos, processos, sistemas e operações, que contribuem para a constituição de saberes, conhecimentos, valores e práticas sociais indispensáveis ao exercício de uma vida de cidadania plena" (BRASIL, 1998, p. 6).

Assim, fica claro que se tornar um professor de uma determinada área não requer apenas o domínio do conhecimento específico desta área. A atenção a um ensino contextualizado e interdisciplinar na educação básica exige dos cursos de formação de professores uma elaboração e vivência curricular pautada na articulação entre o ensino superior e o de nível básico, tomando-se por base um trabalho cooperativo e colaborativo. Para um trabalho docente em consonância com a base nacional comum, orienta-se para a formação de professores, o planejamento de uma base comum nacional. Esta base, 
desenvolvimento de sólida formação teórica e interdisciplinar em educação de crianças, adolescentes, jovens e adultos(as) e nas áreas específicas de conhecimento científico quanto pela unidade entre teoria e prática e pela centralidade do trabalho como princípio educativo na formação profissional, como também pelo entendimento de que a pesquisa se constitui em princípio cognitivo e formativo e, portanto, eixo nucleador dessa formação (BRASIL, 2015, p. 7).

A compreensão de que o futuro professor de educação básica pode pesquisar sobre o ensino que ministra, abre, sobremaneira, as possibilidades de aprofundamento da formação docente inicial à luz de aspectos específicos do seu futuro campo de trabalho: a escola básica. Esta instituição complexa tem requerido dos novos professores conhecimentos e iniciativas que esse novo profissional recém-formado desconhece, por vezes, completamente. O atual professor de História precisa orientar sua prática para além dessa área específica, buscando diálogos e práticas interdisciplinares, precisa efetivar uma prática que leve em consideração as diferenças cognitivas, físicas e culturais de seus alunos e precisa enxergar-se como corresponsável pela gestão da escola e em determinados momentos tornando-se, ele mesmo, o principal gestor, conforme princípios da autonomia escolar, especificamente os da gestão democrática. Dessa forma, a base comum nacional:

\footnotetext{
Deve, ainda, considerar a vivência da gestão democrática, o compromisso social, político e ético com projeto emancipador e transformador das relações sociais e a vivência do trabalho coletivo e interdisciplinar, de forma problematizadora. Tais concepções articulam as diretrizes, definições, metas e estratégias do PNE e, desse modo, devem ser basilares para as diretrizes nacionais para a valorização dos profissionais da educação. (BRASIL, 2015, p. 8).
}

As instituições formadoras, portanto, precisam pensar e discutir sobre a relação entre base nacional comum para a educação básica e a base comum nacional para a formação de professores. A expressão base comum nacional foi cunhada pelo Movimento Nacional de Formação do Educador, no início dos anos de 1980. Scheibe e Bazzo (2001) reconstituem, em seu estudo, a problemática da formação inicial dos professores apresentando orientações relativas à construção de uma base comum nacional para esta formação. As autoras reconstroem esse processo considerando os efeitos da mobilização de entidades 
como a ANFOPE (Associação Nacional pela Formação dos Profissionais da Educação) e o FORUMDIR (Fórum Nacional de Diretores de Faculdades, Centro de Educação ou Equivalentes das Universidades Públicas Brasileiras), as quais permanecem promovendo, até hoje, por meio de uma construção coletiva, o que vem a ser essa base comum nacional para a formação dos profissionais da educação.

As novas Diretrizes Curriculares Nacionais para a Formação Inicial e Continuada dos Profissionais do Magistério da Educação Básica (BRASIL, 2015) apropriam-se da expressão e apontam o que seria considerado chave para essa constituição da base comum nacional tendo em vista a organicidade da formação e a sua articulação com o que se espera na educação básica. Dessa forma, a formação docente seja ela inicial ou continuada deve contemplar:

I - sólida formação teórica e interdisciplinar dos profissionais;

II - a inserção dos estudantes de licenciatura nas instituições de educação básica da rede pública de ensino, espaço privilegiado da práxis docente;

III - o contexto educacional da região onde será desenvolvido;

IV - atividades de socialização e avaliação dos impactos;

$\checkmark$ - aspectos relacionados à ampliação e ao aperfeiçoamento do uso da língua portuguesa e à capacidade comunicativa, oral e escrita, como elementos fundamentais da formação dos professores e à aprendizagem de Libras;

VI - questões socioambientais, éticas, estéticas e relativas à diversidade étnico-racial, de gênero, sexual, religiosa, de faixa geracional e sociocultural como princípios de equidade. (BRASIL, 2015, p. 44).

O desenvolvimento de um projeto de formação docente em História articulado com os sistemas ou redes de ensino e instituições de educação básica requer dos professores formadores e, suas respectivas instituições formativas, ações específicas e planejadas para esse fim. Destacam-se, nesse sentido a participação ativa em Fóruns conjuntos entre as duas instâncias voltadas para o apoio, fortalecimento e melhorias nos cursos de licenciatura ${ }^{2}$. Isso significa buscar a promoção de ações que possibilitem à licenciatura em História uma

2 Na Universidade Federal do Rio Grande do Norte (UFRN) realizamos, em 2015, no bojo das discussões sobre as novas DCN para a formação de professores, quatro Fóruns de Licenciatura, contando com a participação, sobretudo, dos coordenadores de curso de licenciatura e representantes da Secretaria do Estado da Educação e da UNDIME (União Nacional dos Dirigentes Municipais de Educação). 
identidade própria. Concordamos com Fonseca e Zamboni (2008, p. 8) quando declaram que:

Nos últimos anos, estamos vivendo no Brasil um processo de revisão, de críticas, de ampliação e reconhecimento de múltiplos lugares, tempos, processos, sujeitos, saberes e práticas formativas, modos de ensinar e aprender a ensinar, novas metodologias de formar-se, tornar-se professor de História.

A necessidade de uma licenciatura com identidade própria, ou seja, sem ser um apêndice do bacharelado justifica-se, portanto. Além disso, de acordo com as novas DCN para a formação dos profissionais do magistério, o futuro professor de educação básica, deve ir além da sua área específica de formação. O professor de História, além do domínio dos saberes disciplinares (TARDIF, 2000), precisa ter condições de promover desde a integração e interdisciplinaridade curricular, trabalhando, portanto, na perspectiva do trabalho coletivo até a gestão de processos educativos e a organização e gestão de instituições de educação básica. Isso demonstra a importância tanto da formação docente inicial quanto continuada para o exercício do magistério. Para atender a essa concepção articulada de formação inicial e continuada é fundamental que os professores formadores busquem promover a licenciatura com identidade própria. Dessa forma, os cursos de formação de professores de História precisam estabelecer relações com a base comum nacional e ao mesmo tempo possibilitar a existência de componentes curriculares de diferentes formatos e perfis, de modo a

[...] instituir tempos e espaços curriculares diversificados como oficinas, seminários, grupos de trabalho supervisionado, grupos de estudo, tutorias e eventos, atividades de extensão, entre outros capazes de promover e, ao mesmo tempo, exigir dos futuros professores atuações diferenciadas, percursos de aprendizagens variado, diferentes modos de organização do trabalho, possibilitando o exercício de diferentes competências a serem desenvolvidas (BRASIL, Parecer CNE/CP n. 9/2001, p. 52).

Esses aspectos presentes no Parecer n. 09/2001, do CNE, são ratificados pelas novas DCN (BRASIL, 2015, p. 25). É importante aqui registrarmos tais pontos considerando também que os cursos de História são normatizados pelo Parecer n. 492/2001, do CNE (BRASIL, 2001c), que estabelecem as diretrizes 
nacionais para os cursos de História e que se caracterizam pelo silêncio no que se refere à formação do professor da área. Ao discorrerem sobre essas diretrizes específicas da área de História, Fonseca e Couto (2008, p. 108) afirmam que:

\begin{abstract}
O texto enfatiza a formação de um profissional qualificado para o exercício da pesquisa, em consonância com as novas tecnologias, que domina competências e habilidades para o exercício da profissão de historiador e seja capaz de atuar no mundo globalizado. Nas Diretrizes dos Cursos de História, a preocupação central incide na formação do historiador. A ausência, a omissão é a formação de professores de história.
\end{abstract}

Portanto, verificamos um distanciamento entre as DCN-História (2001) e as novas DCN para a formação dos profissionais do magistério (2015). Esse distanciamento já era perceptível em relação à própria LDB (1996) que as precedia, em decorrência da exigência desta pelo respeito a uma base nacional comum, ou seja, da orientação de que os cursos de formação de professores deveriam garantir os conhecimentos da escolaridade básica aos seus egressos em nível tanto de domínio teórico e metodológico, obviamente, mas também de competências básicas.

Esse diagnóstico aponta mais uma vez para a necessidade de estudos e discussões entre os professores formadores tendo em vista o processo de melhorias nos cursos de História, o que inclui formar o profissional da História em permanente articulação com princípios de outra grande área, a Educação. Tomando por base esses aspectos, o Projeto Pedagógico do Curso de licenciatura em História deverá levar em consideração diferentes características e dimensões da iniciação à docência, entre as quais: estudo do contexto educacional; ações que valorizem o trabalho coletivo e interdisciplinar com intencionalidade clara; planejamento e execução de atividades nos espaços formativos desenvolvidas em níveis crescentes de complexidade em direção à autonomia do estudante em formação; participação nas atividades da escola; análise do processo pedagógico e de ensino-aprendizagem dos conteúdos específicos e pedagógicos, além das diretrizes e currículos educacionais da educação básica; leitura e discussão de referenciais teóricos contemporâneos educacionais e de formação; cotejamento e análise de conteúdos que balizam e fundamentam as diretrizes curriculares para 
a educação básica; desenvolvimento, execução, acompanhamento e avaliação de projetos educacionais e escolares (BRASIL, 2015, p. 26).

O futuro professor de História deverá estar capacitado a: trabalhar na promoção da aprendizagem e do desenvolvimento de sujeitos em diferentes fases do desenvolvimento humano nas etapas e modalidades de educação básica; dominar os conteúdos específicos e pedagógicos e as abordagens teóricometodológicas do seu ensino; relacionar a linguagem dos meios de comunicação à educação, demonstrando domínio das tecnologias de informação e comunicação para o desenvolvimento da aprendizagem; atuar na gestão das instituições de educação básica, planejando, executando e avaliando políticas, projetos e programas educacionais assim como o projeto pedagógico da instituição; realizar pesquisas que proporcionem conhecimento sobre os estudantes e sua realidade sociocultural e sobre processos de ensinar e de aprender; sobre propostas curriculares, entre outros. (BRASIL, 2015, p. 27).

Pelo exposto, percebemos a necessidade de que o curso de formação de professores de História possua identidade própria de curso de licenciatura, em que pese a importância da articulação com o curso de bacharelado e mesmo outras licenciaturas. Isso significa também a necessidade de existência de uma "efetiva articulação entre faculdades e centros de educação, institutos, departamentos e cursos de áreas específicas, além de fóruns de licenciatura" (BRASIL, 2015, p. 28), o que implica em mudança de postura de parte dos professores formadores, muitos dos quais repelem essa articulação.

De acordo com as novas DCN, no bojo na proposta de que cursos de licenciatura tenham cara de licenciatura, orienta-se que é preciso que se garanta: "organização institucional para a formação dos formadores, incluindo tempo e espaço na jornada de trabalho para as atividades coletivas e para o estudo e a investigação sobre o aprendizado dos professores em formação" (BRASIL, 2015, p.28). Isso se relaciona com outras necessidades do curso de licenciatura que deveriam ser garantidas, tais como: a existência de coordenação e colegiado próprios e o desenvolvimento de projetos compartilhados com instituições de educação básica. 
Para a formação de professores, conforme as novas DCN (BRASIL, 2015, p. 30), os cursos de licenciatura deverão possuir, no mínimo, 3.200 horas assim distribuídas:

a) 400 (quatrocentas) horas de prática como componente curricular, distribuídas ao longo do processo formativo;

b) 400 (quatrocentas) horas dedicadas ao estágio supervisionado, na área de formação e atuação na educação básica, contemplando também outras áreas específicas, se for o caso, conforme o projeto de curso da instituição;

c) pelo menos 2.200 (duas mil e duzentas) horas dedicadas às atividades formativas estruturadas pelos núcleos I e II, conforme o projeto de curso da instituição;

d) 200 (duzentas) horas de atividades teórico-práticas de aprofundamento em áreas específicas de interesse dos estudantes, como definido no núcleo III, por meio da iniciação científica, da iniciação à docência, da extensão e da monitoria, entre outras, conforme o projeto de curso da instituição.

A partir dessa estrutura, discutimos sobre três aspectos considerados relevantes e que servem de base para proposições de revisão da organização e da operacionalização dos cursos: as atividades de estágio supervisionado, a prática como componente curricular e a curricularização da extensão.

\section{Pesquisando sobre o ensino que ministra: o estágio como iniciação à pesquisa}

Outro aspecto tratado pelas novas DCN é a importância da aprendizagem de procedimentos investigativos e de interpretação da realidade. Para isso, é importante favorecer ao licenciando processos de atuação individuais e coletivos no espaço escolar, proporcionando trocas reflexivas sobre suas práticas. No caso do licenciando em História, o domínio dos elementos teóricos e metodológicos da pesquisa histórica é importante, mas não somente ele. É preciso que o professor de História pesquise sobre o ensino que ministra e o processo de aprendizagem de seus alunos na educação básica. Assim, concordamos com Mello (2000, p. 103) quando afirma:

A dupla relação entre teoria e prática resulta em dois significados próprios ao papel da pesquisa na formação do professor. 
primeiro deles é negativo: a competência para fazer pesquisa pura na área de conhecimento de sua especialidade não é relevante para a formação do professor, ainda que os conhecimentos produzidos pela investigação da área substantiva o sejam, e muito. O segundo significado é positivo: a capacidade de pesquisar dentro da área de especialidade aplicada ao ensino, refletir sobre a atividade de ensinar e formular alternativas para seu aperfeiçoamento é indispensável para o futuro professor. Com isso, compreende-se que os objetos da pesquisa nos cursos de formação docente são o ensino e a aprendizagem do conteúdo dos componentes curriculares da educação básica.

Com base nessa perspectiva, segundo as novas Diretrizes, o egresso de um curso de licenciatura deverá estar capacitado, entre outras coisas, a:

\begin{abstract}
XI - realizar pesquisas que proporcionem conhecimento sobre os estudantes e sua realidade sociocultural; sobre processos de ensinar e de aprender, em diferentes meios ambiental-ecológicos; sobre propostas curriculares; e sobre organização do trabalho educativo e práticas pedagógicas, entre outros;

XII - utilizar instrumentos de pesquisa adequados para a construção de conhecimentos pedagógicos e científicos, objetivando a reflexão sobre a própria prática e a discussão e disseminação desses conhecimentos; (BRASIL, 2015, p. 27).
\end{abstract}

O importante é que o futuro professor de História seja encorajado a fazer de sua prática um elemento significativo no contexto de sua formação. Para isso, a identidade do curso de licenciatura sem ser um apêndice do bacharelado é necessária, requerendo para tanto, entre outras coisas, que o licenciando seja inserido no seu futuro campo profissional desde o início da graduação e que experimente, a partir da metade do curso, um estágio supervisionado com projeto consistente, no qual, saberes, conhecimentos e experiências possam ser orientados por princípios tanto de iniciação à docência quanto de pesquisa sobre a própria prática profissional.

A formação docente com base em experiências de investigação é defendida tanto pela produção acadêmica (ANDRÉ, 2006; BECKER e MARQUES, 2010; CALEFFE e MOREIRA, 2006; MORAES e LIMA, 2004) quanto por orientações curriculares anteriores ao ano de 2015. Em 2001 declarava-se, por exemplo, que:

A formação de professores para os diferentes segmentos da escola básica tem sido realizada muitas vezes em instituições que não valorizam a prática investigativa. Além de não manterem nenhum tipo de pesquisa e não perceberem a dimensão criativa que 
emerge da própria prática, não estimulam o contato e não viabilizam o consumo dos produtos da investigação sistemática. Com isso, a familiaridade com os procedimentos de investigação e com o processo histórico de produção e disseminação de conhecimento é, quando muito, apenas um item a mais em alguma disciplina teórica, sem admitir sua relevância para os futuros professores. Essa carência os priva de um elemento importante para a compreensão da processualidade da produção e apropriação de conhecimento e da provisoriedade das certezas científicas (BRASIL, 2001a).

Dessa forma é que defendemos que o estágio supervisionado precisa ser executado mediante a existência de um projeto formativo próprio e consistente, tendo em vista promover a formação de um docente que reflete sobre a ação e na ação, sendo, assim, capaz de compreender seguramente o complexo universo escolar e enfrentar rápida e conscientemente as diversas situações em seu ambiente de trabalho. O caminho mais indicado para tanto, é o da iniciação à pesquisa sobre o ensino que ministra. Dessa forma é que insistimos que:

Trabalhar os estágios supervisionados como lugar de pesquisa objetiva criar condições para que os futuros professores tenham consciência da importância social do docente; criticidade acerca dos próprios saberes, percebendo limitações e as consequências daí decorrentes; e, domínio de mecanismos para tratar seus conhecimentos como objeto de ensino e pesquisa, fazendo da sua própria prática pedagógica um processo de investigação permanente (AZEVEDO, 2010, p. 246).

Para um período de 400 horas de estágio supervisionado é possível e necessário que o trabalhemos como uma proposta metodológica de formação, segundo a qual a construção de projetos pelos licenciandos possa contemplar as funções de ensino e pesquisa, partindo do conhecimento dos futuros docentes sobre a realidade escolar e fundamentando-se nos dados teóricos adquiridos ao longo do curso, de modo a interagir com os interesses da comunidade escolar onde atua por meio do estágio. Dessa maneira, esperamos que o futuro docente de História sinta-se capacitado a examinar o seu próprio ensino, com vistas a uma mudança nas práticas em prol do êxito dos objetivos de aprendizagem dos seus futuros alunos e, assim, consequentemente, evite a adoção de uma rotina de trabalho distante dos alunos e, por vezes, fragmentada e descontextualizada, sem relação com a vida dos alunos do ensino básico. 
Estágio como iniciação à pesquisa sobre a própria prática docente, sobre o ensino que se ministra, sobre o processo de aprendizagem dos alunos no ensino básico, envolve, necessariamente, o exercício da reflexão sobre a própria profissão e é base para um processo formativo contextualizado. Estágio como iniciação à pesquisa torna-se, portanto, um meio articulador dos conhecimentos característicos da área específica de formação (História), e da área mais ampla de atuação do futuro docente, a Educação.

A proposta de organização dos estágios que toma por base a prática de pesquisa constitui-se em um desafio para todos os envolvidos com o processo formativo. É preciso que se avance acerca da visão que se tem sobre formação de professores. É necessário que licenciandos e seus formadores percebam que um profissional da História pode realizar pesquisa sobre o ensino que pratica, sobre a aprendizagem efetivada por seus alunos, sobre como se ensina História em uma dada realidade escolar, sobre o que significa estudar História para um aluno do Ensino Fundamental e Médio, por exemplo. Muitos são aqueles que, ao pensar em pesquisa, mesmo em curso de licenciatura, só conseguem associá-la à pesquisa específica da ciência de referência. O resultado disso pode ser uma confusão entre projeto de pesquisa e projeto pedagógico o qual toma por base apenas os conteúdos de História a serem ensinados.

Outra confusão a ser evitada em uma proposta formativa nesses termos refere-se ao tipo de pesquisa a ser desenvolvida pelos futuros professores. Caleffe e Moreira (2006, p. 16-17) bem explicam essa diferenciação:

[...] a pesquisa realizada pelo professor a que nos referimos é a pesquisa que o professor pode conduzir no contexto da prática profissional imediata, com o objetivo de melhorar sua prática pedagógica, desenvolver novas estratégias de ensino e buscar soluções para os problemas que afetam a aprendizagem do aluno, ajudando os gestores da educação a entender melhor o contexto em que ocorrem o ensino e a aprendizagem.

Essa experiência desenvolvida por meio do estágio supervisionado muito contribui para levar o futuro professor a melhor entender as vivências em uma realidade escolar bem como a ter maior clareza sobre as implicações resultantes da sua prática na escola na função de docente. Dessa maneira é que concordamos com André (2006, p. 124), quando afirma que: "[...] Já que no 
início da docência podem ser recuperadas muitas práticas vividas na formação profissional, é preciso utilizar, na formação inicial, uma metodologia presidida pela pesquisa, que leve à aprendizagem da reflexão educativa e que vincule constantemente teoria e prática". Trabalhar o estágio supervisionado como iniciação à pesquisa torna-se um caminho para tanto.

Não podemos considerar o estágio supervisionado um momento pontual da formação ou uma atividade complementar para conclusão do curso. Ele deve ser entendido como um componente total do curso, constituído e constituinte das dimensões do ensino, da pesquisa e da extensão. Mas, para que ele seja trabalhado como um espaço político-pedagógico privilegiado de construção da práxis, adotando, para tanto, procedimentos de iniciação à pesquisa e ao ensino, um fato a considerarmos é a importância de que o aluno, ao chegar ao estágio supervisionado, já possua relativa maturidade acadêmica acerca de diferentes aspectos relativos à docência na educação básica. Esse amadurecimento voltado para o efetivo exercício profissional é completamente possível e deve ocorrer ao longo do curso. O caminho mais adequado para isso é o da concretização da prática como componente curricular desde os primeiros instantes de ingresso na graduação.

\section{Vivências docentes desde sempre: a prática como componente curricular}

Nada mais adequado a um curso de licenciatura do que discutir a dimensão da prática da docência. No entanto, a falta de clareza sobre princípios epistemológicos que fundamentam as práticas pode levá-las ao completo silenciamento. É preciso clareza sobre a definição de prática no PPC do curso de licenciatura. O que implica na consistência das concepções de prática e das ações propostas com esse fim dos professores das disciplinas específicas da licenciatura.

A definição de prática como componente curricular pelo coletivo formador da licenciatura poderá se constituir no eixo formativo para a docência. A 
ausência desse eixo tem se constituído no maior problema dos cursos de licenciatura, segundo Gatti (2010).

Conforme as novas DCN de 2015, que reiteram o estabelecido em 2001, a prática docente deve assumir, desde o início do curso, uma dimensão pedagógica fundamental e para tanto deve ser tratada como "componente curricular". Isso pressupõe uma perspectiva transversal de trabalho orientado pela investigação entre teoria e prática em (e entre) todos os componentes curriculares ou disciplinas do curso.

A dimensão da prática da docência é muito mais complexa do que possa parecer inicialmente, visto que ela não se refere, por exemplo, a uma rotina de fazeres de um professor simplesmente. Tal dimensão baseia-se em bases teóricas que apontam para uma relação entre teoria e prática, orientando o papel do professor para o estabelecimento de uma maior proximidade com o processo de aprendizagem dos seus alunos. Estudos de Schön (2000) respaldados na epistemologia da prática influenciaram pesquisas na área de Educação, especialmente, com foco na formação de professores. A orientação básica dessa perspectiva é o processo reflexivo sobre a prática docente que possibilitaria ao docente construir conhecimento sobre o seu próprio ofício. A reflexão na ação, sobre a ação e sobre a própria reflexão na ação caracterizam a epistemologia da prática, a qual vem influenciando as reformas nos cursos de formação de professores no Brasil, sobretudo, no atual milênio.

A defesa de tratamento próprio e permanente à dimensão prática da formação aparece em estudos de outros pesquisadores da área como Tardif (2000, 2002), ao apregoar saberes próprios para o exercício da docência, e Nóvoa (1992) ao discutir o que chama de simetria invertida, conceito adotado pelas diretrizes curriculares nacionais para a formação de professores no Brasil desde 2001 (BRASIL, 2001a, 2001b).

Essa dimensão da prática como componente curricular não se confunde com o modelo aplicacionista do conhecimento, a partir do qual o futuro professor "aplicaria" em sala de aula (geralmente no estágio), o que aprendeu com base em seus estudos teóricos, em uma completa desvinculação entre teoria e prática. Para uma melhor compreensão sobre essa nova dimensão da prática, é válido 
considerarmos o que declara o Conselho Nacional de Educação em seu Parecer n. 28/2001:

[...] deve ser planejada quando da elaboração do projeto pedagógico e seu acontecer deve se dar desde o início da duração do processo formativo e se estender ao longo de todo o seu processo. Em articulação intrínseca com o estágio supervisionado e com as atividades de trabalho acadêmico, ela concorre conjuntamente para a formação da identidade do professor como educador. Esta correlação teoria e prática é um movimento contínuo entre saber e fazer na busca de significados na gestão, administração e resolução de situações próprias do ambiente da educação escolar (BRASIL, 2001b, p. 11).

Fica clara, assim, a distinção entre prática como componente curricular e estágio supervisionado, posto que este passa a ser considerado mesmo como o momento de contato efetivo com o exercício profissional durante a formação inicial. O estágio supervisionado passa a ser entendido como:

[...] o tempo de aprendizagem que, através de um período de permanência, alguém se demora em algum lugar ou ofício para aprender a prática do mesmo e depois poder exercer uma profissão ou ofício. Assim o estágio curricular supervisionado supõe uma relação pedagógica entre alguém que já é um profissional reconhecido em um ambiente institucional de trabalho e um aluno estagiário. Por isso é que este momento se chama estágio curricular supervisionado (BRASIL, 2001b, p. 11).

Real (2012), ao bem analisar diferentes instrumentos normativos do Conselho Nacional de Educação, relativos à formação docente, aponta a prática como componente curricular como algo amplo, como elemento estruturador ao longo de um curso e não como algo passível de ser enquadrado em uma disciplina acadêmica simplesmente:

[...] é possível sinalizar que a criação de uma disciplina intitulada "prática de ensino" não parece atender aos princípios requeridos pela política nacional de formação de professores que está em curso. Nesse mesmo sentido, não deve ocorrer a criação de disciplinas de caráter prático. A dimensão prática parece que deve vir diluída ao longo do curso entre as disciplinas de caráter propositivo, estabelecendo uma relação dialética entre teoria e prática (REAL, 2012, p. 60). 
As pesquisas na área têm avançado $e$, hoje, há consenso sobre a necessidade de uma formação que articule teoria e prática como alicerce para a compreensão e resolução de questões concernentes aos processos de ensinar e aprender. Esse contexto leva-nos a uma nova maneira de conceber a instituição formativa e, por consequência a formação do professor e o seu papel na escola. Contudo, como bem afirma Ghedin (2012, p. 1018) "embora os esforços e as conquistas no campo das pesquisas ao longo desses anos, a proposição de uma formação que atenda as necessidades do trabalho docente foram muito mais discutidas do que verdadeiramente incorporadas nos espaços de formação de professores". Ou seja, mudam-se discursos, elaboram-se propostas, mas na prática pouco acontece.

Diniz-Pereira (2011) analisa as origens das dificuldades de se compreender e se seguir o princípio da indissociabilidade teoria-prática na formação docente, e nesse sentido, o autor afirma que "recebemos uma herança cultural muito forte que tende a separar e hierarquizar as atividades de cunho teórico e intelectual, de um lado, e as atividades práticas, manuais e laborais, de outro" (2011, p. 212). A análise do autor, que toma por base estudos de John Dewey, chega até à Grécia Antiga para mostrar as origens da separação entre teoria e prática na cultura ocidental.

A ênfase na dimensão prática relativa à docência não significa "reforçar as ideias conservadoras e retrógradas que limitam a formação docente ao mero treinamento de habilidades necessárias ao ensino, ou seja, concepções meramente técnicas e instrumentais sobre a formação de educadores" (DINIZPEREIRA, 2011, p. 213). Essa perspectiva refere-se a um movimento de profissionalização do trabalho docente, iniciado mais precisamente na década de 1980, nos Estados Unidos e no Canadá.

Entre os princípios comuns desse movimento, têm-se: conceber o ensino como uma atividade profissional apoiada em um sólido repertório de conhecimentos, entender a prática profissional como um lugar de formação e de produção de saberes pelos práticos e estabelecer ligação entre as instituições universitárias de formação e as escolas da Educação Básica. (DINIZ-PEREIRA, 2011, p. 213)

Essa situação em que muito se discute, mas pouco se efetiva, aparece bem claramente no estudo em que Gatti (2010) analisa a formação de 
professores no Brasil, considerando quatro aspectos: o da legislação relativa a essa formação; as características socioeducacionais dos licenciandos; as características dos cursos formadores; e, os currículos e ementas de licenciaturas. As conclusões da autora indicam consideráveis tensões quanto às condições formativas de professores e sua relação com o exercício do trabalho docente, ao ponto de indicar a necessidade de que se promova "uma verdadeira revolução nas estruturas institucionais formativas e nos currículos da formação". Assim, continua a autora:

As emendas já são muitas. A fragmentação formativa é clara. É preciso integrar essa formação em currículos articulados e voltados a esse objetivo precípuo. A formação de professores não pode ser pensada a partir das ciências e seus diversos campos disciplinares, como adendo destas áreas, mas a partir da função social própria à escolarização - ensinar às novas gerações o conhecimento acumulado e consolidar valores e práticas coerentes com nossa vida civil. A forte tradição disciplinar que marca entre nós a identidade docente e orienta os futuros professores em sua formação a se afinarem mais com as demandas provenientes da sua área específica de conhecimento do que com as demandas gerais da escola básica, leva não só as entidades profissionais como até as científicas a oporem resistências às soluções de caráter interdisciplinar para o currículo (GATTI, 2010, p. 1375).

Dessa forma é que consideramos a prática como componente curricular como uma espécie de liga que dará ao curso de formação de professores uma identidade própria e concordamos com os membros do $1^{0}$ Fórum das Licenciaturas da UFRN, ocorrido em 2015, quando defendem que é preciso:

- que os cursos se afastem de uma visão conservadora, elitista e preconceituosa de formação que ainda possuem.

- que sejam propostas ações efetivas de mudanças para as licenciaturas para que se evitem proposições apenas no plano da retórica.

- que o processo de reformulação das licenciaturas busque estabelecer diálogos reais e concretos com as escolas públicas de educação básica e suas demandas.

- que a formação docente seja feita em articulação com o contexto escolar e, assim, tome também por base o currículo da escola básica e não apenas o saber da ciência de referência. (UFRN, 2015, p. 1-2).

Essas indicações não se constituem em ações pontuais, significam uma mudança ampla de postura a ser adotada pelos professores formadores e, logo, institucionalizada como política de formação de professores no ensino superior. 
Indicações como essas são desafios ainda em muitas de nossas instituições de formação de professores. Mas que precisam ser enfrentados e uma possibilidade para isso é começarmos a implementação efetiva da prática como componente curricular. O futuro professor não pode começar a pensar na docência somente no final do curso (estágio supervisionado) ou mesmo depois de formado. É preciso pensar e vivenciar experiências de prática profissional com todos os seus professores formadores, ao longo dos diferentes componentes curriculares do curso de formação. Ou seja, como bem declara Diniz-Pereira (2011, p. 204): "[...]. Desse envolvimento com a realidade prática se originam problemas e questões que devem ser levados para discussão nas disciplinas teóricas. [...]".

A prática como componente curricular possibilita melhor formarmos 0 professor. Uma vez que em um curso de licenciatura, o futuro docente não pode continuar experimentando o lugar de aluno, já vivido durante a sua educação básica. Estamos formando o professor e não um aluno. Logo, é imprescindível que desde o início do curso, o licenciando vivencie experiências de prática profissional. O sujeito não pode se formar professor vivendo o papel de aluno. A prática como componente curricular objetiva assim tornar a licenciatura coerente com a sua função: formar professores! Concordamos, assim, com Mello (2000, p. 102) quando afirma que:

Ninguém facilita o desenvolvimento daquilo que não teve oportunidade de aprimorar em si mesmo. Ninguém promove a aprendizagem de conteúdos que não domina, a constituição de significados que não compreende nem a autonomia que não pôde construir.

De forma mais objetiva e direta, declara a autora (2000, p. 103), "[...]. A prática do curso de formação docente é o ensino, portanto cada conteúdo que é aprendido pelo futuro professor em seu curso de formação profissional precisa estar relacionado com o ensino desse mesmo conteúdo na educação básica". Um caminho competente e necessário para isso é o da contextualização do conhecimento para o público de ensino básico. É necessário que o licenciando de História compreenda a importância do estudo de povos como os astecas e incas a partir do século XIII, assim como do estudo da descolonização do continente africano no século $X X$, ou da escravização de povos africanos no Brasil por séculos, para o aluno de educação básica, sujeito geral que, por meio da escola, 
busca a promoção da sua formação para a vida e para o trabalho na sociedade atual. Se ao menos este exercício de reflexão e argumentação sobre o conteúdo fosse realizado em todas as disciplinas específicas da área de formação durante a graduação, o licenciando teria melhores condições de perceber-se como futuro docente, aprofundando de forma mais consistente e significativa, a partir da metade do curso, a sua experiência formativa por meio do estágio supervisionado. Dessa maneira, estaria o futuro professor iniciando, de fato, a construção da sua postura/identidade docente. Do contrário, permanecerá constante no estágio a presença de licenciandos apreensivos e inseguros quanto ao exercício da profissão que escolheram.

A prática que se apregoa como componente curricular não se confunde com o estágio supervisionado e nem mesmo com a prática de ensino. O Parecer CNE/CES n. 15/2005 ratifica essa compreensão ao afirmar que:

[...] a prática como componente curricular é o conjunto de atividades formativas que proporcionam experiências de aplicação de conhecimentos ou de desenvolvimento de procedimentos próprios ao exercício da docência. Por meio destas atividades, são colocados em uso, no âmbito do ensino, os conhecimentos, as competências e as habilidades adquiridos nas diversas atividades formativas que compõem o currículo do curso. As atividades caracterizadas como prática como componente curricular podem ser desenvolvidas como núcleo ou como parte de disciplinas ou de outras atividades formativas (BRASIL, 2005, p. 3).

O estágio supervisionado corresponde a um período de culminância de um processo de práticas iniciado desde o primeiro momento do curso e corresponde ao pleno exercício da profissão, orientado por um professor formador com atuação em ensino e pesquisa sobre a docência, preferencialmente, e supervisionado por um docente experiente com atuação em escola básica de modo a possibilitar um retorno imediato (feedback) ao licenciando acerca das fragilidades e potencialidades da sua prática docente. Como componente curricular, a prática precisa ser compreendida como uma dimensão do conhecimento. "A idéia a ser superada, enfim, é a de que o estágio é o espaço reservado à prática, enquanto, na sala de aula se dá conta da teoria" (BRASIL, Parecer CNE/CP n. 9/2001, p. 23).

A perspectiva de articulação da dimensão prática, no interior das disciplinas do curso, transcende o estágio (e a concepção de estágio como pura prática) e 
tem como finalidade promover a articulação das diferentes práticas em uma proposta interdisciplinar dentro do próprio curso, destacando o método de observação e reflexão, para entender e atuar em situações contextualizadas, sejam acadêmicas ou escolares.

O importante é que o futuro professor seja encorajado a fazer de sua prática um elemento significativo no contexto de sua formação. Como licenciando, ele precisa enxergar-se como um profissional em formação e não como um aluno. Nesse sentido, a dimensão prática deve fazer parte da organização dos seus estudos e precisa ser assumida pelos professores, mas também pelo próprio licenciando. Conforme defende Mello (2000, p. 104):

\begin{abstract}
A prática deverá estar presente desde o primeiro dia de aula do curso superior de formação docente, por meio da presença orientada em escolas de educação infantil e ensinos fundamental e médio ou de forma mediada pela utilização de vídeos, estudos de casos e depoimentos ou qualquer outro recurso didático que permita a reconstrução ou simulação de situações reais.
\end{abstract}

Prática, portanto, não é uma ação a ser desenvolvida única e exclusivamente nos estágios supervisionados. É preciso que, como formadores, façamos aquilo que orientamos que nossos alunos o façam: trabalhar em grupo. A prática como componente curricular no curso de licenciatura obriga maior interlocução entre os professores do curso, requer o exercício constante e complexo do diálogo e exige de quem coordena o curso, a liderança na promoção do processo contínuo de avaliação da licenciatura em questão.

Os desafios da formação de professores, hoje, vão além dos aspectos teóricos e metodológicos. Ao pensarmos na ampliação da carga horária das licenciaturas, a partir de 2015, para 3.200 horas, é preciso planejarmos a reorganização curricular dos cursos tendo em vista possibilitarmos tanto o alcance das demandas formativas quanto o cumprimento do curso sem um aumento quantitativo e engessador de disciplinas curriculares reforçando a lógica disciplinar. Dessa forma, partindo do princípio da indissociabilidade do ensino, da pesquisa e da extensão como base da formação no ensino superior, levantamos a curricularização da extensão como mais uma possibilidade formativa a ser considerada, discutida e regulamentada nas instituições formadoras. 


\title{
4. Curricularização da extensão: iniciação à docência em diferentes tempos e espaços
}

A legislação relativa à organização do ensino superior, dos últimos anos, tem possibilitado limites no que se refere às licenciaturas. É um exemplo disso o abrandamento da vinculação entre ensino, pesquisa e extensão como base da formação em nível superior. Como resultado tem-se a possibilidade de organização curricular baseada exclusivamente no ensino.

\begin{abstract}
Merecem destaque, especialmente, os Decretos n. 2.306, de 19 de agosto de 1997 e n. 3.860, de 9 de julho de 2001 e, atualmente, o Decreto no 5.773, de 9 de maio de 2006, que flexibilizam a estruturação da educação superior no país e, como decorrência, o princípio da indissociabilidade entre ensino, pesquisa e extensão como seu parâmetro básico. Tais Decretos incidiram, substantivamente, na organização acadêmica, com desdobramentos efetivos na formação de professores. Além desses Decretos, temos, no campo educacional, a efetivação de Resoluções, Portarias e outros dispositivos regulatórios que engendram mudanças na cultura institucional e, portanto, nas dinâmicas de gestão e organização desse nível de ensino (BRASIL, 2015, p. 6).
\end{abstract}

Diante da ampliação da carga horária da licenciatura, conforme as novas DCN, e ainda, considerando o estímulo ao crescimento das matrículas e as diferenças existentes entre as instituições formadoras no País, esse estado de coisas torna-se preocupante. Sem um processo de fato proativo de proposições e avaliação das ações curriculares diversificadas nos cursos de formação de professores, a formação docente ocorrida no ensino superior tenderá a se reduzir à função do ensino, desvinculada, em certa medida, do processo de produção de conhecimento e sem (ou com frágil) contextualização relativa a situações profissionais reais.

[...]. Como decorrência desse processo, ocorreram processos e disputas de concepções na ação institucional relativa à formação de professores, destacando-se o lócus onde deveria ocorrer suas prioridades, diretrizes, dinâmica curricular, relação entre formação e valorização profissional, entre outras. É importante situar que a priorização dos bacharelados, nas diversas áreas, contribuiu para a redução de espaço dos cursos de licenciatura e, em muitos casos, para o consequente empobrecimento da formação de professores, agravado, ainda, pelo fato de grande parte das IES formadoras faculdades e centros universitários - pautar sua atuação no âmbito 
do ensino, secundarizando a pesquisa e a extensão. (BRASIL, 2015, p. 6).

Contudo, apesar da existência de tal legislação, a LDB (1996) e o PNE (2014-2024) possibilitam-nos novos ares sobre essa discussão. De acordo com a atual Lei de Diretrizes e Bases, a extensão é parte obrigatória da formação do aluno do ensino superior e deve fazer parte do PPC do curso, inclusive, como componente curricular. Dessa maneira, os docentes da licenciatura podem, mediante o trabalho coletivo e, especialmente junto à coordenação e ao colegiado do curso, propor muitas e diversificadas possibilidades formativas atendendo tanto às necessidades reais de formação dos licenciandos e às demandas sociais por conhecimento escolarizado, quanto ao atual reordenamento de carga horária que estabelece como mínimo, o elevado quantitativo de 3.200 horas. Outro aspecto sobremaneira relevante é o fato de poder integrarmos, se não toda, mas a maior parte dos licenciandos do curso e não apenas continuarmos possibilitando a apenas uma minoria o acesso a ações extensionistas.

O atual Plano Nacional de Educação (BRASIL, 2014), por sua vez, mais precisamente na Meta 12, Estratégia 7, define, como mínimo, 10\% do total de créditos curriculares do curso de graduação, a serem efetivados por meio de programas e projetos de extensão. Esse encaminhamento desafia professores formadores a um processo de revisão curricular consistente e, dessa forma, pode ser considerado como uma grande alternativa para que as licenciaturas aproximem seus projetos formativos dos sistemas, redes e instituições de ensino da educação básica. Formar o profissional da História na licenciatura, por exemplo, tem que significar formar um professor de educação básica. Em que pese a obviedade desta relação, ela não vem se constituindo em uma realidade em algumas instituições formadoras, tornando-se assim, apenas em uma suposta obviedade. Assim, com o propósito de contribuir para a definição da licenciatura com cara de licenciatura, é que defendemos que ações de extensão tomadas como componente curricular podem ajudar a todos os envolvidos com esse processo de formação de professores.

A organização curricular baseada predominante ou exclusivamente no ensino resulta no estabelecimento de elevado número de disciplinas acadêmicas, 
por vezes marcadas por uma lógica disciplinar na qual não há relações entre saberes, experiências, sujeitos e instituições. A proposição de ações extensionistas articuladas a processos de iniciação à docência na licenciatura visa, justamente, possibilitar uma alternativa à rigidez da organização disciplinar, ao possibilitar o planejamento de variadas vivências formativas em diferentes tempos e espaços.

Como afirmam Fonseca e Couto (2008, p. 124), ao se referirem ao currículo dos cursos de formação de professores de História:

[...]. Pensar em conteúdos multidisciplinares e interdisciplinares ou assumir o desafio de quebrar a lógica disciplinar, pensar em espaços interculturais que possam ressignificar as dimensões da teoria e da prática - bem como o ensino alicerçado à pesquisa - e pensar em transgressões metodológicas são passos significativos e desconcertantes, que "devemos" considerar.

É com base em posições como essas que considerarmos como fator relevante a curricularização de ações de extensão que tomam como foco a formação docente. Mas, como transformarmos a extensão em componente curricular? Obviamente, torna-se necessário definir a carga horária do curso que será destinada a ações extensionistas ou já identificar em que disciplinas, entre às já existentes, poderia ser dedicada uma carga horária específica para uma ação de extensão. Outra alternativa seria mesmo a oferta em projetos de extensão, planejados como unidades curriculares integrais, obrigatórias ou optativas, para os licenciandos. Uma terceira possibilidade, externa ao curso e, por isso, alvo de regulamentação, seria a validação de atividades de extensão realizadas pelos estudantes independentemente de orientações da coordenação do curso. A exigência de regulamentação decorre da necessidade de que a extensão seja inserida no curso de forma qualificada, fortalecendo as práticas formativas de forma contextualizada.

A extensão é sem dúvida uma das formas mais efetivas de a Universidade assumir e cumprir sua missão social, no que se refere à formação de cidadãos aptos a enfrentar os problemas do seu tempo. A formação universitária deve ultrapassar os limites da sala de aula abrangendo o trabalho efetivo com a comunidade onde está inserida, proporcionando, dessa forma, ao discente, uma verdadeira vivência universitária. Apesar disso, as ações de extensão não estão 
entre as mais bem consideradas e avaliadas no meio universitário. O êxito da curricularização da extensão, por isso, perpassaria um outro processo, o da valorização do trabalho acadêmico de extensão, a começar pela valorização no esforço de trabalho docente, consubstanciado na definição e registro de carga horária adequada.

Não é incomum encontrarmos problemas na execução de ações extensionistas em instituições de ensino superior. Trindade, Lima e Vicente (2007, p. 74 ) bem demonstram esse aspecto, ao afirmarem que:

\begin{abstract}
Desde a sua criação, ela foi concebida como um apêndice, inexistindo obrigatoriedade para sua realização. Releva-se a face assistencialista que a mesma adquiriu com o passar do tempo, como responsável pela diminuição do status que se goza. E, mesmo em dias atuais, a atividade continua difícil de ser materializada.
\end{abstract}

Silva (2002) garante que uma das grandes lutas dos docentes que advogam a favor da extensão é fazer com que ela saia da posição assistencialista que a caracteriza. Afirma o autor que a extensão universitária se encontra nesta situação desde o seu surgimento, o que provoca certa aversão por parte de alguns profissionais no que se refere à sua adoção enquanto procedimento metodológico de ensino. Dessa forma, é preciso que consideremos, como afirmam Andrade e Silva (2004) que, na relação extensionista, os indivíduos em sociedade são sujeitos do conhecimento, que, juntos com os membros da universidade podem, em conjunto, problematizar e estabelecer espaços de convivência onde o saber possa ser produzido e socializado. Portanto, por meio de ações de extensão, inseridas no currículo da licenciatura de forma qualificada, poderemos viabilizar a existência de uma relação de caráter transformador entre universidade e sociedade, entre ensino superior e educação básica, entre a formação docente na licenciatura e o efetivo exercício profissional da docência em História na educação básica. 


\section{Considerações finais}

As novas Diretrizes Curriculares Nacionais para a formação dos profissionais do magistério da Educação Básica (BRASIL, 2015), como fica explícito no documento, apontam para a necessidade de que, nos cursos de licenciatura, trabalhemos a reflexão sobre a necessidade de currículos que privilegiem a tematização dos conhecimentos escolarizados, dos saberes e das experiências relativas ao campo profissional da docência. Muitos dos seus encaminhamentos não se constituem em novidade. As novas DCN recuperam e aglutinam o que vários documentos orientadores já apregoavam no tocante à formação docente. Contudo, diante da permanência de velhas práticas encobertas por projetos pedagógicos de curso bem elaborados, mas cujas ações não se efetivavam, as novas DCN estabelecem tempo para implementação. As instituições formadoras terão o prazo de até dois anos para ajustarem seus projetos de curso às demandas sociais e de instituições por formação qualificada.

Ainda temos cursos nos quais a organização bacharelesca do currículo impera, nos quais há visões deturpadas e mesmo preconceituosas em relação às chamadas disciplinas de caráter pedagógico, cursos nos quais há um claro distanciamento e mesmo resistência às tentativas de interlocução entre Departamentos e Centros ou até mesmo a projetos formativos interdisciplinares, cursos nos quais há docentes formadores que não se veem como professores formadores de professores, pois estão mais preocupados ou única e exclusivamente preocupados com a disciplina que ministra na graduação, sem ter qualquer planejamento de ações práticas que contribuam, de fato, para a formação de futuros docentes.

Concluímos retomando a ideia apresentada no título deste artigo e questionamos a partir dela: a formação do docente em História ocorre efetivamente tendo em vista o exercício do magistério do futuro profissional na educação básica? Isso não seria um pressuposto óbvio? Não se forma o professor na graduação para atuação primeira e diretamente na educação básica? Considerando-se que nem sempre essa relação ocorre em algumas instituições formadoras, a obviedade que gostaríamos que existisse no título deste artigo se desfaz. A suposta obviedade do título, portanto, é aqui 
apresentada de forma proposital e, nesse momento, é retomada para que fique como provocação para o pensar e o repensar de ações e para definições curriculares coetâneas às necessidades formativas dos futuros professores de História.

\section{Referências}

ANDRADE, L. A. B.; SILVA, E. P. Extensão universitária: proposição de um conceito e sua aplicação. Revista de extensão. Universidade Federal de Mato Grosso, ano 1, n. 1, p. 24-32, Cuiabá, EdUFMT, 2004.

ANDRÉ, M. Ensinar a pesquisar: como e para quê? In: VEIGA, Ilma P. A. Veiga (Org.). Lições de didática. Campinas: Papirus, 2006, p. 123-134.

AZEVEDO, C. B. Estágio Supervisionado como lugar de pesquisa e suas implicações na formação do professor de História. Linguagens, Educação e Sociedade/UFPI. Teresina, ano, 15, n. 23, p. 215-249, jul./dez-2010.

BECKER, F.; MARQUES, T. B. I. (Org.). Ser professor é ser pesquisador. Porto Alegre: Mediação, 2010.

BRASIL. Parecer CEB/CNE n. 04/1998 relativo às Diretrizes Curriculares Nacionais para o Ensino Fundamental. Brasília: Conselho Nacional de Educação, 29 de janeiro de 1998.

BRASIL. Parecer CNE/CP n. 9/2001, institui Diretrizes Curriculares Nacionais para a Formação de Professores da Educação Básica, em nível superior, curso de licenciatura, de graduação plena. Brasília: CNE, 2001a.

BRASIL. Parecer CNE/CP n. 28/2001, dá nova redação ao Parecer CNE/CP 21/2001, que estabelece a duração e a carga horária dos cursos de Formação de Professores da Educação Básica, em nível superior, curso de licenciatura, de graduação plena. Brasília: CNE, 2001b.

BRASIL. Parecer CNE/CES n. 492/2001. Diretrizes Curriculares Nacionais dos cursos de Filosofia, História, Geografia, Serviço Social, Comunicação Social, Ciências Sociais, Letras, Biblioteconomia, Arquivologia e Museologia. Brasília: CNE/CES, 2001c.

BRASIL. Parecer CNE/CES n. 15/2005 - Relatório de esclarecimento ao Governo do Estado da Bahia/Universidade Estadual do Sudoeste da Bahia. Brasília: Conselho Nacional de Educação, 2005.

BRASIL. Lei n. 13005, de 25 de junho de 2014 - aprova o Plano Nacional de Educação - PNE. Brasília: Ministério da Educação, 2014. 
BRASIL. Parecer CNE/CP n. 02/2015 relativo às Diretrizes Curriculares Nacionais para a Formação Inicial e Continuada dos Profissionais do Magistério da Educação Básica. Brasília: Conselho Nacional de Educação, 9 de junho de 2015.

CALEFFE, L. G.; MOREIRA, H. Metodologia da pesquisa para o professor pesquisador. Rio de Janeiro: DP\&A, 2006.

DINIZ-PEREIRA, J. E. A prática como componente curricular na formação de professores. Educação, Santa Maria, v. 36, n. 2, p. 203-218, maio/ago. 2011.

FONSECA, S. G., COUTO, R. C. do. A formação de professores de História no Brasil: perspectivas desafiadoras do nosso tempo. In: ZAMBONI, Ernesta; FONSECA, Selva G. (Org.). Espaços de formação do professor de História. Campinas: Papirus, 2008, p. 101-130.

GATTI, B. Formação de professores no Brasil: características e problemas. Educação \& Sociedade, Campinas, v. 31, n. 113, p. 1355-1379, 2010.

GHEDIN, E. et. al. Formação inicial de professores da educação básica no Brasil: trajetória e perspectivas. Rev. Diálogo Educ., Curitiba, v. 12, n. 37, p. 997-1026, set./dez. 2012

MELLO, G. N. de. Formação inicial de professores para a educação básica - uma revisão necessária. São Paulo em Perspectiva. São Paulo, v. 14, n. 1, p. 98-110, jan./mar.2000.

MORAES, R. de; LIMA, V. M. do R. (Org.). Pesquisa em sala de aula: tendências para a educação em novos tempos. 2 ed. Porto Alegre: EDIPUCRS, 2004.

NÓVOA, A. (Org.). Os professores e sua formação. Lisboa: Dom Quixote, 1992.

REAL, G. C. M. A prática como componente curricular: o que isso significa na prática? Educação e Fronteiras On-Line, Dourados, v. 2, n. 5, p. 48-62, maio/ago. 2012.

SCHÖN, D. Educando o profissional reflexivo: um novo design para o ensino e a aprendizagem. Porto Alegre: Artes Médicas, 2000.

SILVA, E. W. O papel da extensão no cumprimento da função social da universidade. In: SILVA, E. W.; FRANTZ, W. As funções sociais da universidade: o papel da extensão e a questão das comunitárias. Ijuí: Ed. Unijuí, 2002. p. 103217.

TARDIF, M. Saberes profissionais dos professores e conhecimentos universitários: elementos para uma epistemologia da prática profissional dos professores e suas conseqüências em relação à formação para o magistério. Revista Brasileira de Educação, n. 13, p. 5-24, jan-abr. 2000. Saberes docentes e formação profissional. Petrópolis: Vozes, 2002. 
TRINDADE, D. da S.; LIMA, R. R.; VICENTE, S. S. Ensino, Extensão e Pesquisa: representação sociais de professores de uma universidade pública de Mato Grosso. Cuiabá: EdUFMT, FAPEMAT, 2007.

UFRN. Nota do $1^{0}$ Fórum das Licenciaturas da UFRN: Inclusão e diversidade étnico-racial nos cursos de licenciatura da UFRN. Natal, Universidade Federal do Rio Grande do Norte, 26 de março de 2015.

ZAMBONI, E.; FONSECA, S. G. Apresentação. In: ZAMBONI, E.; FONSECA, S. G. (Org.). Espaços de formação do professor de História. Campinas: Papirus, 2008, p. 7-15.

Recebido NO SISTEMA em 19 de novembro de 2015 Aprovado NO SISTEMA em 18 de dezembro de 2015

( $O$ dossiê vem sendo produzido, incluindo avaliação pelos pares, desde dezembro de 2014) 